\title{
High prevalence of Leptospira spp. in sewer rats (Rattus norvegicus)
}

\author{
L. H. KRØJGAARD ${ }^{1,2,3 *}$, S. VILLUMSEN ${ }^{2}$, M. D. K. MARKUSSEN ${ }^{3}$, J. S. JENSEN ${ }^{2}$, \\ H. LEIRS ${ }^{3,4}$ AND A.-C. HEIBER G ${ }^{3}$ \\ ${ }^{1}$ Department of Biology, University of Copenhagen, Denmark \\ ${ }^{2}$ Statens Serum Institut, Department of Bacteriology, Mycology and Parasitology, Copenhagen, Denmark \\ ${ }^{3}$ Danish Pest Infestation Laboratory, Department of Integrated Pest Management, University of Aarhus, \\ Denmark \\ ${ }^{4}$ Department of Biology, University of Antwerp, Belgium
}

(Accepted 24 March 2009)

\section{SUMMARY}

Earlier studies on the ecology of leptospirosis in temperate regions focused mainly on free-ranging rats in rural areas. Here we report on the occurrence of Leptospira spp. in Rattus norvegicus living in sewers in a suburban area in Copenhagen, Denmark. In 2006-2007, about 30 rats were captured in sewers at each of six different locations. Rat kidneys were screened by PCR for pathogenic Leptospira spp. In one location no infected rats were found, whereas the prevalence in the remaining five locations ranged between $48 \%$ and $89 \%$. Micro-agglutination tests showed that serogroup Pomona, Sejroe, and Icterohaemorrhagiae were the most common. Infection was related to age with the highest prevalence observed for adult rats but there was no difference in infection rate between sexes, suggesting primarily environmental transmission. Since most reported rat problems in urban areas are related to sewer rats, the surprisingly high level of infection calls for an increased public health concern.

Key words: Disease reservoirs, Leptospira spp., polymerase chain reaction (PCR), rats, sewers.

\section{INTRODUCTION}

Leptospirosis is one of the most prevalent zooanthroponoses worldwide. The agents of leptospirosis are the pathogenic species of Leptospira [1]. Leptospirosis is a disease affecting multiple organs, and the clinical symptoms and signs are often nonspecific influenza-like symptoms. In the most severe cases, the disease is known as Weil's disease, a

\footnotetext{
* Author for correspondence: L. H. Krøjgaard, Statens Serum Institut, Department of Bacteriology, Mycology and Parasitiology, building 43, room 317, Artillerivej 5, 2300 Copenhagen S, Denmark.

(Email: lkd@ssi.dk)
}

syndrome characterized by multi-organ failure and a mortality of $5-15 \%$ [1]. The disease is probably heavily underdiagnosed in humans, due to the often non-specific symptoms, low accessibility of rapid diagnostic methods and lack of awareness among clinicians [2].

Infected animals excrete Leptospira in the urine, and the primary route for further transmission of the infection is through contact with urine or water contaminated with urine of infected animals [2-4]. Rodents are an important reservoir of Leptospira, and the commensal brown rat (Rattus norvegicus), which is closely linked to human activities, is believed to be the reservoir host of the pathogenic Leptospira 
Table 1. Location and period of trapping of rats

\begin{tabular}{lllll}
\hline \hline Area & Municipality & Area & $\begin{array}{l}\text { Surface } \\
\text { area }\left(\mathrm{km}^{2}\right)\end{array}$ & Trapping period \\
\hline B1 & Lyngby-Taarbæk & Ørholm & $0 \cdot 30$ & July 2006 \\
B2 & Lyngby-Taarbæk & Virum & $1 \cdot 60$ & March 2007 \\
B3 & Rødovre & Roskildevej & $1 \cdot 00$ & February 2007 \\
B4 & Rødovre & Damhusdalen & $0 \cdot 14$ & November 2006 \\
B5 & Copenhagen & Østerbro & $0 \cdot 08$ & November 2006 \\
B6 & Copenhagen & Nørrebro & $0 \cdot 19$ & November 2006 \\
\hline \hline
\end{tabular}

interrogans serovar Icterohaemorrhagiae known to cause severe leptospirosis in humans and dogs $[2,5-7]$.

In cities of the UK and in Denmark, $70-90 \%$ of complaints concerning rats are related to defective sewers and the number of reported rat problems in cities is increasing $[8,9]$. Through defective sewers, rats can enter people's homes, factories, have contact with foodstuffs, etc., thus presenting a risk of transmission of Leptospira to humans. Despite these facts, only very limited information is available on the biology of rats living in sewers, their role as carriers of zoonotic agents in general and Leptospira spp. in particular. The present study on $R$. norvegicus caught in sewers is the first since Seguin et al. [10] tested 91 rats sampled in sewers in Lyon, France. They found that $17 \%$ had positive titres against Leptospira spp. using the microscopic agglutination test (MAT), while only $7 \%$ were found infected by culturing of kidneys. Our study is the first of its kind to use polymerase chain reaction (PCR) to detect Leptospira spp. in rats living in sewers.

Earlier studies of surface rodent populations have primarily been conducted in tropical regions, where the burden of leptospirosis is severe [1, 11-17]. Some of the most recent surveys from temperate climates have been performed in the UK [18], Switzerland [19] and Baltimore, USA [20]. Webster et al. [18] tested rats from farms while Adler et al. [19] and Easterbrook et al. [20] tested rodents and shrews from city areas. These studies showed varying proportions of infected animals, ranging from $13 \%$ [19] to $65 \%$ [20], partly explained by different methods (ELISA, MAT, culture, silverstaining, IFA, PCR). In 1986, the latest prevalence study on Danish rats was undertaken. This was conducted on surface rats and the seroprevalence of $L$. interrogans serovar Icterohaemorrhagiae was found to be as low as 3\% [21]. The observed differences in prevalence in the different studies may reflect geographical and habitat variation, but may also be due to the variation in sensitivity and specificity of different diagnostic techniques used [18-21].

\section{MATERIALS AND METHODS}

\section{Sampling of rats}

From the summer of 2006 until spring of 2007, rats ( $R$. norvegicus) caught in sewers in six locations (B1-B6) in Copenhagen city and its suburbs were sampled (Table 1). Sewer locations were selected based on signs and reports of recent rat activity in the sewers. Metal wire-cage live-traps $(61 \times 21 \times 24 \mathrm{~cm}$ or $46 \times 18 \times 20 \mathrm{~cm}$ ) were placed in sewer manholes in a deactivated state $1-2$ weeks prior to trapping, in order to make rats accustomed to the traps. Traps were placed free from the water flow on wooden platforms. Balls of bird seed, coated in tallow, were used as bait. After the acclimation period, traps were activated and checked daily. The exact position of trapping was noted for each individual rat. Trapped rats were transferred to the laboratory, weighed, sexed and caged singly in wire-bottomed steel cages $(31.5 \times 19 \times 26 \mathrm{~cm})$ suspended $7 \mathrm{~cm}$ above trays which allowed collection of faeces and urine in the trays below the cages. Rats were, therefore, never in contact with droppings from other rats. For descriptive reasons and in order to investigate possible differences in infection rates related to age, rats were divided into subgroups based on body weight: juveniles were defined as rats weighing $<100 \mathrm{~g}$, sub-adults weighing between $100 \mathrm{~g}$ and $200 \mathrm{~g}$ and adults with a weight $>200 \mathrm{~g}$ as described by Webster et al. [18]. Rats were fed a standard rat and mouse laboratory diet ( $5 \mathrm{mg}$ vitamin $\mathrm{K}_{3} / \mathrm{kg}$; Altromin No. 1324 Fortified; Chr. Petersen A/S, Denmark) with tap water available ad libitum. As the rats were originally collected for the purpose of screening for 
resistance to anticoagulant rodenticides, the kidneys were sampled at autopsy, after anticoagulant resistance testing (bromadiolone blood-clotting response test combined with a VKORC1 ARMS-PCR assay) [9]. It should be noted that all rats were submitted to the same resistance testing protocol, although there is no suggestion that the resistance testing could affect the level of Leptospira infection.

Rats were killed with $\mathrm{CO}_{2}$ and the kidneys were removed under sterile conditions using sterilized scissors and tweezers. Both kidneys were stored at $-80{ }^{\circ} \mathrm{C}$ until DNA purification.

\section{Precautions to avoid PCR product carry-over}

Strict physical separation between sample preparation, PCR setup and analysis laboratories was maintained. All procedures in the DNA extraction and PCR preparation were performed in bio safety level II laboratory benches under sterile vertical laminar air flow (LAF bench).

Handling of tissues until proteinase $\mathrm{K}$ treatment was done in a separate building. The rest of the DNA and PCR preparations were done in a separate LAF bench in a separate building. DNA preparation and PCR were performed on separate days. The subsequent gel-electrophoresis was performed by laboratory technicians not involved in the DNA and PCR preparation, and in a separate building. Sterile filter tips (ART; SDS, Sweden) were used in all sample manipulations, and all surfaces in the PCR setup laboratory were regularly wiped with a $0 \cdot 5 \%$ hypochlorite solution and exposed to UV light between sessions with the purpose of destroying contaminating DNA.

Positive controls had low copy numbers, containing 20 and 200 genome copies of L. interrogans, respectively. At least two negative controls were included in each run. Furthermore, all PCR reactions were performed with dUTP instead of dTTP, allowing for enzymatic prevention of PCR product carry-over with uracil- $N$-glycosylase.

\section{Purification of DNA}

For DNA extraction, a 145-160 mg transverse section including all functional layers of the kidney was isolated from either the left or right kidney and DNA was purified according to the manufacturer's protocol (DNeasy blood and tissue kit; Qiagen Ltd, UK). Since we used a larger amount of starting material than recommended by the manufacturer, the volume of lysis buffer was adjusted accordingly. An aliquot of the lysed product corresponding to the recommended volume was used for final DNA extraction.

\section{PCR}

For detection of Leptospira spp. a conventional PCR was used, based on the primers G1: 5'-CTG AAT CGC TGT ATA AAA GT-3' and G2: 5'-GGA AAA CAA ATG GTC GGA AG-3' as described previously [22]. The primers amplify a $285 \mathrm{bp}$ fragment of the $\operatorname{Sec} Y$ gene and have previously been shown to amplify DNA from at least six pathogenic Leptospira spp. namely $L$. interrogans, L. noguchii, L. santarosai, L. meyeri, L. weilii and L. borgpetersenii [22]. PCR reactions were performed in total volumes of $100 \mu \mathrm{l}$ : G1 $2 \mu \mathrm{l}(20 \mathrm{~mm}), \quad \mathrm{G} 22 \mu \mathrm{l}(20 \mathrm{~mm}), \mathrm{MgCl}_{2} 5 \mu \mathrm{l}$ (50 mM), Platinum buffer $10 \mu \mathrm{l}$, dUTP mix $10 \mu \mathrm{l}$ $(25 \mu \mathrm{M}$ dATP, $25 \mu \mathrm{M}$ dCTP, $25 \mu \mathrm{M}$ dGTP, $50 \mu \mathrm{M}$ dUTP), Milli-Q water $61 \mu 1$, Platinum Taq $0 \cdot 4 \mu \mathrm{l}$ (5 U/ $/ \mu 1$ ) and template DNA $10 \mu \mathrm{l}$. The cycling reactions were performed on a GeneAmp PCR system 9600 (Applied Biosystems, USA) using a touch-down PCR profile consisting of an initial hot start at $94^{\circ} \mathrm{C}$ for $2 \mathrm{~min}$ followed by 10 cycles with denaturation at $95{ }^{\circ} \mathrm{C}$ for $30 \mathrm{~s}$, annealing at $60{ }^{\circ} \mathrm{C}$ for $15 \mathrm{~s}$ with a $1{ }^{\circ} \mathrm{C}$ decrement per cycle and elongation at $72{ }^{\circ} \mathrm{C}$ for $30 \mathrm{~s}$, followed by 40 cycles with an annealing temperature at $50{ }^{\circ} \mathrm{C}$ and a final extension step for $5 \mathrm{~min}$ at $72{ }^{\circ} \mathrm{C}$. PCR products were visualized by ethidium bromide staining followed by electrophoresis on a $2 \%$ agarose gel (Nusieve GTG agarose, Seakem Lonza, Switzerland). Fragment sizes were estimated using a 100 bp ladder (New England BioLabs, USA).

\section{MAT}

Sera from a randomly chosen subsample of 17 rats from different locations were serologically tested by an accredited MAT as previously described [3]. Serum was tested against 16 serovars belonging to 11 pathogenic, one intermediate pathogenic and one saprophytic serogroup. The serogroups used were Patoc, Icterohaemorrhagiae (three different strains), Sejroe (two different strains), Poi, Canicola, Ballum, Bratislava, Pomona, Grippotyphosa, Saxkoebing, Bataviae, Hardjo and Hurstbridge. The end-point titre was determined as the highest serum dilution showing agglutination of at least $50 \%$ of the cells, i.e. a +2 reaction. A serum sample was considered 


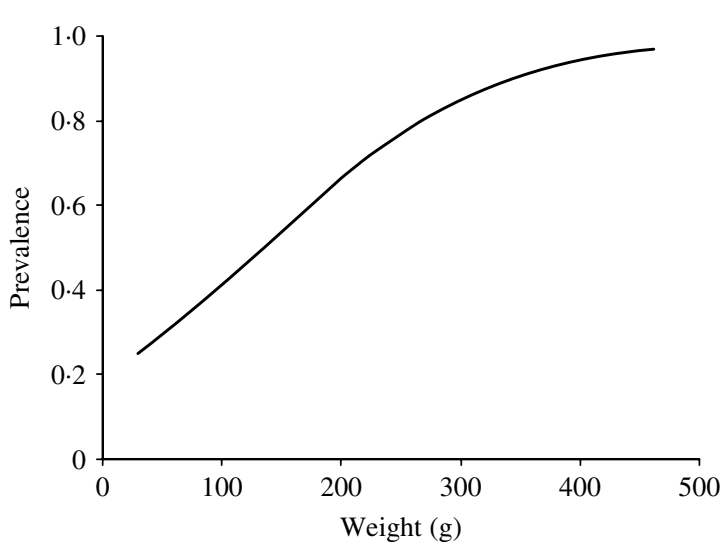

Fig. 1. Predicted prevalence of infected rats by weight, based on the body weight and infection status of the caught rats.

positive at a titre $\geqslant 1: 100$, following cut-off values that were standard for human serology in the same laboratory. Due to lack of serum, dilution was only performed until a positive end-point reaction at $1: 100$ for two rats and 1:450 for one rat.

\section{STATISTICS}

A logistic regression model was fitted to data using the PROC logistic (SAS 9.1; SAS Institute, USA) to analyse the effect and possible interaction of the following parameters; location, body weight and sex on the outcome, presence or absence of Leptospira spp., respectively.

Only locations B2-B6 were included in the analysis because no rats with Leptospira spp. infection were seen in area B1. The best model was selected based on backwards elimination of effect parameters and parameters with significant $(P<0.05)$ effect on the outcome were included in the final analysis.

In order to investigate the effect of age on the infection rate, we considered body weight to be a substitute parameter of the age of the rat. The predicted probability of infection as a function of weight was calculated based on the model above. The results are expressed both as a graph (Fig. 1) and fitted to a model were the relative change in infection rate according to weight intervals could be described by an odds ratio $(\mathrm{OR})$.

\section{RESULTS}

A total of 196 rats (92 males and 104 females) from the six different locations were tested for the presence of Leptospira spp. by PCR. The sex was determined
Table 2. Number and percentage of infected rats at the different trapping sites

\begin{tabular}{llcc}
\hline \hline Locality & $\begin{array}{l}\text { No. of rats } \\
\text { tested }\end{array}$ & $\begin{array}{l}\text { No. of rats } \\
\text { positive }\end{array}$ & \% positive \\
\hline B1 & 48 & 0 & 0 \\
B2 & 25 & 20 & 80 \\
B3 & 19 & 17 & 89 \\
B4 & 31 & 15 & 48 \\
B5 & 35 & 24 & 69 \\
B6 & 38 & 27 & 71 \\
Total & 196 & 103 & 53 \\
\hline \hline
\end{tabular}

for all 196 rats and body weight for 183 of the 196 rats.

A total of 104 rats $(53 \%)$ were found to be infected. At one location none of the rats were infected with Leptospira spp., while the prevalence in the remaining five locations differed from $48 \%$ to $89 \%$ (Table 2). At some of the positive locations, Leptospira spp.infected and non-infected rats were sampled in manholes which where located alongside each other. However, in some locations, we also sampled infected and non-infected rats from the same manhole.

We found no significant difference in the prevalence between the two sexes but observed a significantly $(P<0.05)$ higher prevalence in area $\mathrm{B} 3$ compared to the other four areas where infection with Leptospira occurred.

The number of individuals in each of the three categories, juvenile, sub-adult and adult was 28,41 and 114 , respectively. The three age groups were all represented in each location (Table 3). The mean body weight of all rats was $232 \mathrm{~g}$ with a range of $30-462 \mathrm{~g}$.

In the five areas where infected rats were found, the percentage of infected juveniles was $16 \%(3 / 19)$. In the sub-adult group 21/31 (68\%) were infected and in adults the numbers were 80/96 (83\%).

A highly significant correlation $(P<0 \cdot 001)$ between body weight and probability of infection was found; this correlation was described by a model that gave an increase in OR of 1.33 (95\% confidence interval $1 \cdot 18-1 \cdot 50)$ per $25 \mathrm{~g}$ increase in weight (Fig. 1).

\section{MAT}

Seventeen rats were tested by MAT of which 16 showed agglutinations at a titre between 100 and 1000 ; six were $>100$. The same 16 rats were positive by PCR and one remaining rat was negative. Of the six rats with a titre $>1: 100$ the one having the 
Table 3. Number of juvenile, sub-adult and adult rats caught in the six localities $(B 1-B 6)$

\begin{tabular}{lccccccc}
\hline \hline & B1 & B2 & B3 & B4 & B5 & B6 & Total \\
\hline Juveniles & $9(0)$ & $3(1)$ & $3(2)$ & $5(0)$ & $6(0)$ & $2(0)$ & 28 \\
Sub-adults & $10(0)$ & $4(4)$ & $4(3)$ & $15(8)$ & $5(3)$ & $3(3)$ & 41 \\
Adults & $16(0)$ & $18(15)$ & $12(12)$ & $11(7)$ & $24(21)$ & $33(24)$ & 114 \\
Total & 35 & 25 & 19 & 31 & 35 & 38 & 183 \\
\hline \hline
\end{tabular}

Values in parentheses are the number of infected rats.

highest titre was against Icterohaemorrhagiae. The remaining 10 rats with titre 1:100 most often showed agglutination towards the serogroups Pomona, Sejroe, and/or Icterohaemorrhagiae.

\section{DISCUSSION}

This survey shows that Leptospira spp. is highly prevalent in rats caught in sewers. In five of the six examined sewer locations, $48-89 \%$ of the examined rats were infected with Leptospira spp. The serovars belonging to the serogroup Icterohaemorrhagiae are considered among the most pathogenic to humans and are commonly found in rats [5, 15, 16, 23]. A subpopulation of 17 rats was tested by MAT and the highest titres were found against the serogroups Pomona, Sejroe and Icterohaemorrhagiae. Significant differences in the prevalence of Leptospira-infected rats were found between some of the locations (location B1 and B3).

Although Leptospira-infected rats seemed to be prevalent in the sewers, one location, B1, differed markedly from the others as none of the 48 rats captured here were infected. Since rats are known to be chronically infected with at least $L$. interrogans serovar Icterohaemorrhagiae [5, 6], they continue to shed the bacteria in urine. Thus, the non-occurrence of Leptospira in the B1 population indicates that the infection has been absent for a prolonged period of time, and seasonal variation is unlikely to play a major role in explaining its presence or absence. Therefore, the data suggest that the rats at $\mathrm{B} 1$ have lived as a population which has not been in contact with infected populations for quite some time. Leptospira has not been able to be maintained above a critical level in those rats.

In comparison with previous surveys the prevalence found in the five infected sewer locations of this study was high. Sunbul et al. [14] have reported a Leptospira spp. infection rate of $27 \%$ by PCR in Turkish rats caught along the seashore. Studies where MAT has been used have similarly shown infection rates of $21 \%$ and $41 \%$ in Israeli and Thai rats, respectively $[12,16]$. In a survey of urban settings in Brazil [11], a higher prevalence was found in rats ( $R$. norvegicus). They found that $80 \%$ were positive by culture and/or PCR/MAT.

One reason for the high infection rate in the rats caught in sewers could be an accidental sampling of individuals belonging to the same deme, assuming that there is a higher transmission rate within a deme than between demes. The sampling would then not be representative for the population within each location as a whole. We do not yet know if sewer rat populations are structured into family groups as are rat populations living outside the sewers [24]. However, unpublished results from an ongoing study on the biology of rats in sewers indicate that most of these rats may be limited in their movements and thus may form smaller family units. With this knowledge, our data do not suggest a gathering of infected rats in particular 'hotspots', rather, infected and noninfected rats were dispersed more or less evenly within the various sampling locations and thus probably representative of numerous family units.

We found a rise in the prevalence of infected rats with increasing age, with only $16 \%$ of juvenile rats and $83 \%$ of the adult rats being infected with Leptospira spp. This is in accord with the findings of other authors $[15,16,20,23]$. The low infection rate in juvenile rats indicates that transplacental transmission of Leptospira is of minor importance, if at all, in sewer rats. It is probable that the increase in infection rate with age is explained by a longer period of exposure to the environment, increased social behaviour in adults and the fact that infection with at least L. interrogans serovar Icterohaemorrhagiae in rats is found to be chronic $[5,6]$.

The present study raises many questions regarding environmental and behavioural factors influencing 
the transmission of Leptospira infection in rats. While the study was not designed to address this issue, and thus definitive conclusions on this topic cannot be drawn, there are some interesting indications. Leptospira spp. are known to survive in wet surroundings and despite the presence of detergents, etc. in wastewater the sewers could provide a habitat conducive for the transmission of Leptospira. Such a mechanism, where both sexes are equally exposed to possible infection, would be consistent with the fact that we did not find any differences in prevalence between males and females. Other studies have examined sexual differences. Nutall et al. [25] found no sexual difference in infection rates, whereas Easterbrook et al. [20] suggested that female rats should be more prone to infection, based on the findings in urban rats of Baltimore, USA. Moreover, living in a sewer system limits movements which can cause more frequent interactions between the rats. This, and the constant presence of contact with water which facilitates survival of excreted Leptospira, can be the cause of the observed high prevalence compared to studies on rats living on the surface.

\section{CONCLUSION}

In conclusion, the present study reports a high overall prevalence $(53 \%)$ of Leptospira spp. in rats caught in sewers, ranging from $48-89 \%$ in five of the six locations studied, while in one location no Leptospira infection was observed. We found a strong correlation between prevalence and body weight and observed a rapid increase in the prevalence post-infancy. No gender difference was found.

High prevalence of Leptospira infection in rats caught in sewers should be a great cause of concern for health authorities, and also in cities with temperate climate. Since most surface rats in urban areas, with which humans may have contact, originate from the sewer population, there is a considerable and probably underestimated risk for transmission of this zooanthroponosis. Ageing sewer systems and growing problems with the control of rat populations, e.g. due to resistance to rodenticides, may aggravate this problem.

\section{ACKNOWLEDGEMENTS}

This project is part of an ongoing project concerning the biology of sewer rats. The sewer rat project is funded by the Environmental Protection Agency, the 'Kommunernes Momsfond' and the Danish Pest Infestation Laboratory (DPIL), University of Aarhus, Denmark. The molecular work and identification of Leptospira spp. was funded by DPIL and Statens Serum Institut (SSI), Denmark. The authors thank staff members Folmer Jensen, Iver Skadborg and Sarah Adams at DPIL as well as Berit Jensen and PCR laboratory technicians at SSI for providing technical assistance in animal handling and testing. Additional thanks to Claus Bo Svendsen, SSI and Steen Ethelberg, SSI for support with statistical analysis, and to supervisors Jes Søe Pedersen, Copenhagen University and Karen A. Krogfelt, SSI, for helpful discussions during the process.

\section{DECLARATION OF INTEREST}

None.

\section{REFERENCES}

1. Levett PN. Leptospirosis. Clinical Microbiology Reviews 2001; 14: 296-326.

2. WHO. Human leptospirosis: guidance for diagnosis, surveillance and control. World Health Organization, 2003, pp. 2-21.

3. Hartskeerl RA, et al. International Course on Laboratory Methods for the Diagnosis of Leptospirosis, 5th edn. Amsterdam: KIT, 2006, pp. 1-9.

4. Twigg GI, Cuerden CM, Hughes DM. Leptospirosis in British wild mammals. Symposium Zoological Society of London 1968; 24: 75-98.

5. Faine S, et al. Leptospira and Leptospirosis, 2nd edn. Melbourne, Australia: MediSci, 1999, 73 pp.

6. Twigg GI. Rat-borne leptospirosis in wildlife and on farm. Mammal Review 1973; 3: 37-42.

7. Borg-Petersen C, Jacobsen E. Infection with spirochetes of Weil's type in dogs [in Danish]. Ugeskrift for Lager 1937; 45: 1189-1194.

8. Mayer A. Rats in sewers out of sight out of mind? Professional Pest Controller 2004; 37: 4-7.

9. Heiberg A-C. Anticoagulant resistance: a relevant issue in sewer rat (Rattus norvegicus) control? Pest Management Science 2009; 65: 444-449.

10. Seguin B, et al. Epidemiologic evaluation of a sample of 91 rats (Rattus norvegicus) captuned in the sewers of Lyon. Zentralblatt für Bakteriologie Mikrobiologie und Hygiene 1986; 261 : 539-546.

11. Faria MT, et al. Carriage of Leptospira interrogans among domestic rats from an urban setting highly endemic for leptospirosis in Brazil. Acta Tropica 2008; 108: $1-5$.

12. Doungchawee G, et al. Survey of leptospirosis of small mammals in Thailand. Southeast Asian Journal of Tropical Medicine and Public Health 2005; 36: 15161522. 
13. Michel V, Branger C, Andre-Fontaine G. Epidemiology of leptospirosis. Revista Cubana de Medicina Tropical 2002; 54: 7-10.

14. Sunbul M, et al. Rattus norvegicus acting as a reservoir of Leptospira interrogans in the Middle Black sea region of Turkey, as evidenced by PCR and presence of serum antibodies to Leptospira strain. Scandinavian Journal of Infectious Diseases 2001; 33: 896-898.

15. Levett PN, et al. Surveillance of leptospiral carriage by feral rats in Barbados. West Indian Medical Journal 1998; 47:15-17.

16. Lindenbaum I, Eylan E. Leptospirosis in Rattus norvegicus and Rattus rattus in Israel. Israel Journal of Medical Sciences 1982; 18: 271-275.

17. Dalu JM, Feresu SB. Domestic rodents reservoirs of pathogenic leptospira on two city of Harare farms: preliminary results of bacteriological and serological studies. Belgian Journal of Zoology 1997; 127: 105-112.

18. Webster JP, Ellis WA, MacDonald DW. Prevalence of Leptospira spp. in wild brown rats (Rattus norvegicus) on UK Farms. Epidemiology and Infection 1995; 114: 195-201.
19. Adler H, et al. Prevalence of Leptospira spp. in various species of small mammals caught in an inner-city area in Switzerland. Epidemiology and Infection 2002; 128: 107-109.

20. Easterbrook JD, et al. A survey of zoonotic pathogens carried by Norway rats in Baltimore, Maryland, USA. Epidemiology and Infection 2007; 135: 1192-1199.

21. Lund M. Leptospira spp. in rats from fish farms and farms [in Danish]. Miljøprojek No. 79, 1987, pp. 5-27.

22. Gravekamp C, et al. Detection of seven species of pathogenic leptospires by PCR using two sets of primers. Journal of General Microbiology 1993; 139: 16911700.

23. Thiermann AB. Incidence of leptospirosis in the Detroit rat population. American Journal of Tropical Medicine and Hygiene 1977; 26: 970-974.

24. Klemann N, Pelz H-J. The feeding pattern of the Norway rat (Rattus norvegicus) in two differently structured habitats on a farm. Applied Animal Behaviour Science 2006; 97: 293-302.

25. Nuttall GHF, et al. Leptospira icterohaemorrhagiae in Oxford rats. Journal of Hygiene 1929; XXIX: 218-226. 